\title{
ASPECTOS MORFOLÓGICOS DA SEMENTE E DO DESENVOLVIMENTO DA PLANTA JOVEM DE Amburana cearensis (Arr. Cam.) A.C. Smith - CUMARU - LEGUMINOSAE PAPILIONOIDEAE ${ }^{1}$
}

\author{
MARIA DO CARMO LEARTH CUNHA²; ROBÉRIO ANASTÁCIO FERREIRA ${ }^{3}$
}

\begin{abstract}
RESUMO - Os objetivos deste trabalho foram descrever e ilustrar os aspectos morfológicos da semente e do desenvolvimento da planta jovem de Amburana cearensis. Os frutos foram coletados de cinco matrizes distantes no mínimo 100m, levando-se em consideração o aspecto fitossanitário e a intensidade de frutificação. $\mathrm{O}$ endocarpo permanece aderido à semente formando uma ala, mesmo após a deiscência; o hilo apresenta fenda longitudinal típica da sub-família; a germinação é do tipo semi-hipógea fanerocotiledonar e, com o desenvolvimento observou-se a presença de uma tuberosidade na raiz primária. Os caracteres descritos e ilustrados mostraram-se bastante homogêneos entre as cinco matrizes, podendo ser empregados para identificação da referida espécie, tanto em trabalhos de laboratório e de produção de mudas quanto em estudos ecológicos.
\end{abstract}

Termos para indexação: morfologia, sementes, plântulas, planta jovem, Amburana cearensis.

\author{
MORPHOLOGICAL ASPECTS OF SEED AND SEEDLINGS DEVELOPMENT OF \\ Amburana cearensis (Arr. Cam.) A.C. Smith - \\ CUMARU - LEUMINOSAE PAPILIONOIDEAE
}

\begin{abstract}
The objectives of this research were to describe and to illustrate the morphological aspects of seeds and the aspects of seedlings development of Amburana cearensis. The fruits were harvested from five trees $100 \mathrm{~m}$ distant each other, considering the sanity aspects and quantity of fruits produced. The endocarp stays attached to the seed like a wing after dehiscence; the hilum showed a longitudinal grove, common in the sub-family; the germination is semi-hypogeous phanerocotylar and the primary root in the seedlings phase is tuberous. The characters described and illustrated were constant between the five trees and can be used to identify the species in laboratory, nursery and ecological studies.
\end{abstract}

Index terms: morphology, seed, seedling, Amburana cearensis.

\section{INTRODUÇÃO}

Amburana cearensis (Arr. Cam.) A.C. Smith, também conhecida como cumaru, amburana de cheiro e cumaru-doCeará, apresenta porte regular, podendo atingir até $10 \mathrm{~m}$ de altura nas regiões de caatinga (Corrêa, 1978 e Lorenzi, 1992) e até 20m na zona da mata (Lorenzi, 1992). Ocorre naturalmente do Nordeste ao Brasil Central, em regiões de caatinga

\footnotetext{
${ }^{1}$ Aceito para publicação em 10/12/2003.

${ }^{2}$ Prof ${ }^{\mathrm{a}}$, M.Sc., Departamento de Engenharia Florestal/CSTR/UFCG; Caixa Postal 64, 58700-700, Patos, PB; e-mail: c.learth@uol.com.br

${ }^{3}$ Prof., Dr., Departamento de Engenharia Agronômica - DEA/UFS; Av. Marechal Deodoro, s/n, Cidade Universitária Prof. José Aloísio Campos, Jardim Rosa Elze, 49100-000, São Cristóvão, SE; e-mail: raf@ufs.br
}

e na floresta pluvial de Minas Gerais, no vale do Rio Doce (Braga, 1976; Corrêa, 1978 e Lorenzi, 1992). De acordo com Tigre (1968), a espécie pode ser recomendada para trabalhos visando a recuperação de áreas degradadas. A madeira é amplamente empregada em serviços de movelaria e marcenaria e, as sementes, em função do odor agradável exalado, são utilizadas para perfumar roupas (Lorenzi, 1992). As sementes são utilizadas, ainda, na medicina caseira como anti-espasmódicas, emanagogas e para o tratamento de doenças reumáticas (Tigre, 1968 e Braga, 1976).

A região semi-árida ocupa áreas consideráveis de todos os estados do Nordeste brasileiro e se estende até Minas Gerais, abrangendo cerca de um milhão de $\mathrm{km}^{2}$. A vegetação dominante nesta área é denominada caatinga, excessivamente heterogênea quanto à fisionomia e estrutura, constituída de 
arvoretas e arbustos decíduos durante a seca, cactáceas, bromeliáceas e ervas, quase todas anuais (Rizini, 1979).

A importância da vegetação nativa desta região é indiscutível, devido a sua multiplicidade de usos, tais como energético, forrageiro, alimentar, medicinal e madeireiro, assim como, para o equilíbrio ecológico. A exploração exercida neste meio tem relação direta com o grau de utilidade das espécies. Por ser essencialmente extrativista, resulta em problemas graves para as espécies mais procuradas. Neste sentido, é necessário a realização de estudos básicos sobre as espécies que compõem este complexo vegetacional, de modo a ampliar o conhecimento de tais espécies. Alguns autores, como Feliciano (1989); Silva e Matos (1991); Araújo e Matos (1991); Silva e Matos (1998) e Ferreira e Cunha (2000), fornecem informações sobre aspectos morfológicos de espécies de caatinga, que podem ser seguramente empregadas em trabalhos de laboratório, para auxiliar na interpretação de testes de germinação, em viveiro, para facilitar o reconhecimento das plântulas e, também, em estudos sobre a ecologia das espécies.

Para os taxonomistas, as diferenças entre as plantas, assim como as mudanças que possam ter em comum, são susceptíveis de avaliação em larga escala pelos caracteres morfológicos. Estes caracteres manifestam-se por componentes estruturais das plantas e, o seu valor aprecia-se pela sua constância. Deste modo, quanto mais constantes, maior a confiança que neles se pode depositar (Lawrence, 1973).

No que diz respeito às sementes, uma grande quantidade de características taxonômicas e filogenéticas são fornecidas por estas. De modo geral, as de emprego taxonômico são as mais superficiais, mas os caracteres internos são de maior interesse na classificação. Têm importância particular a presença ou ausência de endosperma, forma e posição do embrião, número e posição dos cotilédones (Lawrence, 1973). De acordo com Gunn (1972), tanto as características externas quanto as internas das sementes são pouco modificadas pelo ambiente, constituindo-se um critério bastante seguro para identificação.

Os estudos iniciais relacionados às estruturas da semente, especialmente os envoltórios, datam do século XVII (Beltrati, 1992). Para Toledo \& Marcos-Filho (1977), as estruturas morfológicas de um embrião, assim como a posição que ocupa na semente são tão distintas entre os diferentes grupos de plantas, que podem ser seguramente utilizadas para a identificação de famílias, gêneros e até espécies.

A identificação das plantas no estádio juvenil conduz a três direções principais: contribuir para um melhor entendi- mento da biologia da espécie, ampliar os estudos taxonômicos e auxiliar em trabalhos de levantamento ecológico, nos aspectos de regeneração por sementes em condições naturais e, na ocupação e estabelecimento ambiental por qualquer espécie (Salles, 1987). De acordo com o autor, a sobrevivência da plântula, em condições naturais, depende da interação que se estabelecerá entre esta e o ambiente, desde a germinação até o estabelecimento, ambas fases críticas na vida vegetal. Os aspectos morfológicos das plântulas podem ser empregados, tanto para identificação de plantas de uma determinada região, quanto para facilitar a interpretação de testes de germinação em laboratório (Oliveira, 1993).

O reconhecimento de plantas, a partir de plântulas, é uma tarefa que dificilmente é completada, uma vez que os caracteres externos nos estádios iniciais de desenvolvimento podem ser diferentes daqueles observados no indivíduo adulto ou em plantas de espécies e gêneros afins. Normalmente, nesta fase, os indivíduos apresentam semelhanças que dificultam a identificação dos mesmos (Pinheiro, 1986). Do mesmo modo, o estudo de plântulas e plantas é indispensável para a obtenção de dados relevantes aos estudos de regeneração natural (Pinheiro et al., 1989).

Face à relevância de tais estudos, os objetivos deste trabalho foram descrever e ilustrar os aspectos morfológicos da semente e do desenvolvimento da planta jovem de cumaru (Amburana cearensis), com fins de ampliar o conhecimento da flora arbórea da caatinga e subsidiar trabalhos, quer seja em laboratório ou em condições naturais com a referida espécie.

\section{MATERIAL E MÉTODOS}

As sementes foram coletadas nos municípios de Patos PB e Malta - PB e o trabalho foi realizado no Laboratório de Sementes e Viveiro florestal, do Departamento de Engenharia Florestal (DEF), do Centro de Saúde e Tecnologia Rural (CSTR), da Universidade Federal da Paraíba (UFPB).

Foram selecionadas cinco matrizes, distantes no mínimo 100m entre si, levando-se em consideração o estado fitossanitário e a intensidade de frutificação. Os frutos foram coletados diretamente das árvores-matrizes, com auxílio de podão e lona plástica. As sementes mal conformadas e com injúrias foram eliminadas.

Para a descrição morfológica da unidade de dispersão foram escolhidas aleatoriamente 20 unidades de cada matriz, as quais foram medidas com paquímetro $(1 / 0,5 \mathrm{~mm})$, descritas e ilustradas manualmente, com auxílio de lupa binocular. 
Os caracteres morfológicos observados foram: tamanho, forma, coloração, textura, posição do hilo e da micrópila, forma e coloração do embrião, número de cotilédones e eixo hipocótilo-radícula.

Para descrição e ilustração da morfologia e desenvolvimento da plântula e da planta jovem, foram semeadas 100 sementes de cada matriz, em bandejas de polietileno $(32 \times 25 \times 2,5 \mathrm{~cm})$ e mantidas em condições ambiente. O substrato empregado foi areia, peneirada, lavada e esterilizada em estufa a $105^{\circ} \mathrm{C} \pm 5^{\circ} \mathrm{C}$. As bandejas permaneceram sobre bancada até o término do processo germinativo.

Após germinadas, 20 plântulas de cada matriz foram levadas para o Viveiro Florestal e repicadas para sacos de polietileno (32x20x0,12cm), tendo como substrato terra de subsolo, esterco de curral e areia, na proporção 1:1:1. As plântulas permaneceram sob sombrite $60 \%$ durante oito dias e, posteriormente, foram colocadas no sol.

Para as descrições foram tomadas as plântulas e plantas jovens mais vigorosas entre as matrizes e, dentre estas, apenas uma foi utilizada para ilustração.

Foram consideradas três fases para descrição e acompanhamento do desenvolvimento da planta de A. cearensis, de acordo com a metodologia proposta por Feliciano (1989). A primeira fase, considerada germinação, indo desde o intumescimento da semente até emissão dos cotilédones, porém sem os protófilos formados; a segunda fase, caracterizada como plântula, quando o protófilo estava totalmente formado e a terceira fase, a planta jovem, quando do aparecimento do pronomófilo.

Os elementos vegetativos descritos e ilustrados para cada fase foram os sugeridos por Roderjan (1983): raiz, colo, hipocótilo, cotilédones, epicótilo, caule jovem e protófilos de primeira e segunda ordens. O método e os termos empregados estão de acordo com Vidal (1978), Gunn (1981), Kuniyoshi (1983), Roderjan (1983), Barroso (1984), Beltrati (1992) e Barroso (1999).

\section{RESULTADOS E DISCUSSÃO}

Morfologia da semente - A semente é estenospérmica (Beltrati, 1992), com forma variando entre elíptica, oblonga e ovóide e, de acordo com Gunn (1981), é levemente comprimida (Figura 1A-D). O tegumento apresenta textura lenhosa, sendo a testa de coloração marmoreada, rugosa e opaca. O comprimento da semente varia de $12,55 \mathrm{~mm}$ a $17,55 \mathrm{~mm}$ e a largura varia de 8,35mm a 11,50mm. Em seção transversal é elíptica, com lados ovalados e em seção longitudinal é oblonga. O hilo é bem visível (Figura 1C-E), homócromo (sem a camada pulverulenta do endocarpo), localizado lateralmente, próximo à base da semente, numa região mais escura e mais proeminente. A forma do hilo varia entre ovalada e elíptica, sendo na maioria das vezes orbicular e, apresenta fenda longitudinal, que é típica da sub-família (Barroso, 1984). O comprimento do hilo varia de $1,25 \mathrm{~mm}$ a $3,10 \mathrm{~mm}$ e a largura varia de 1,30 a $2,00 \mathrm{~mm}$. Após a retirada do tegumento fica evidente a marca do hilo no embrião. A calaza localiza-se acima do hilo e é pouco perceptível e, a micrópila, localizase numa protuberância abaixo do hilo, em oposição à calaza, sendo, na maioria das vezes imperceptível, devido à camada pulverulenta que recobre a testa. O embrião é axial, invaginado (Figura 1F-H), com cotilédones de forma ovóide, elíptica e oblonga, planos, carnosos, amarelados, lisos, com ápice arredondado e base obtusa. O eixo hipocótilo-radícula é infletido, cônico, curto, articulado entre os lóbulos dos cotilédones e o pólo radicular é mais externo à semente. A semente é exalbuminosa.

A ala, que é formada pelo endocarpo adnato, característico de criptosâmaras (Gunn, 1981 e Barroso, 1984), localiza-se no ápice da semente, de coloração bege claro, nervura dorsal bem saliente, textura membranácea, quebradiça, persistente, com comprimento variando de 25,05mm a 46,65mm (Figura 1C-D). Tal estrutura, demonstra aspecto evolutivo para a dispersão anemocórica (Barroso, 1999). Em analogia à descrição de Vidal (1978), pode ser considerada como paranuclear, em função da posição que ocupa na semente.

Desenvolvimento da plântula (Figura 1I-O) - A germinação tem início com a emissão de raiz primária 5 dias após a semeadura, de coloração amarelo creme, rompendo o tegumento na base da semente, próximo ao hilo; a raiz primária é sinuosa e apresenta pêlos simples, poucos visíveis e esparsos, de coloração branca. Posteriormente, adquire coloração amarelo pardo, tendo início a formação de raízes secundárias. O hipocótilo é curto, cilíndrico e com lenticelas próximo à inserção dos cotilédones. Os cotilédones são de coloração amarelo creme, envolvidos pelo tegumento; quando rompem o tegumento, são opostos, unilaterais, isófilos, adquirindo coloração verde, com bordo inteiro, sem nervação, passando de sub-sésseis a curto peciolados. O epicótilo é visível a partir do $8^{\circ}$ dia de semeadura, tendo inicialmente coloração amarelada, cilíndrico, liso, brilhante e, quando se inicia a formação dos protófilos, adquire coloração verde claro, com densa pilosidade esbranquiçada, somente visto sob lupa; apresenta catáfilo na sua porção mediana, sendo este séssil e lanceolado. Os protófilos são opostos e, às vezes, alternos, 

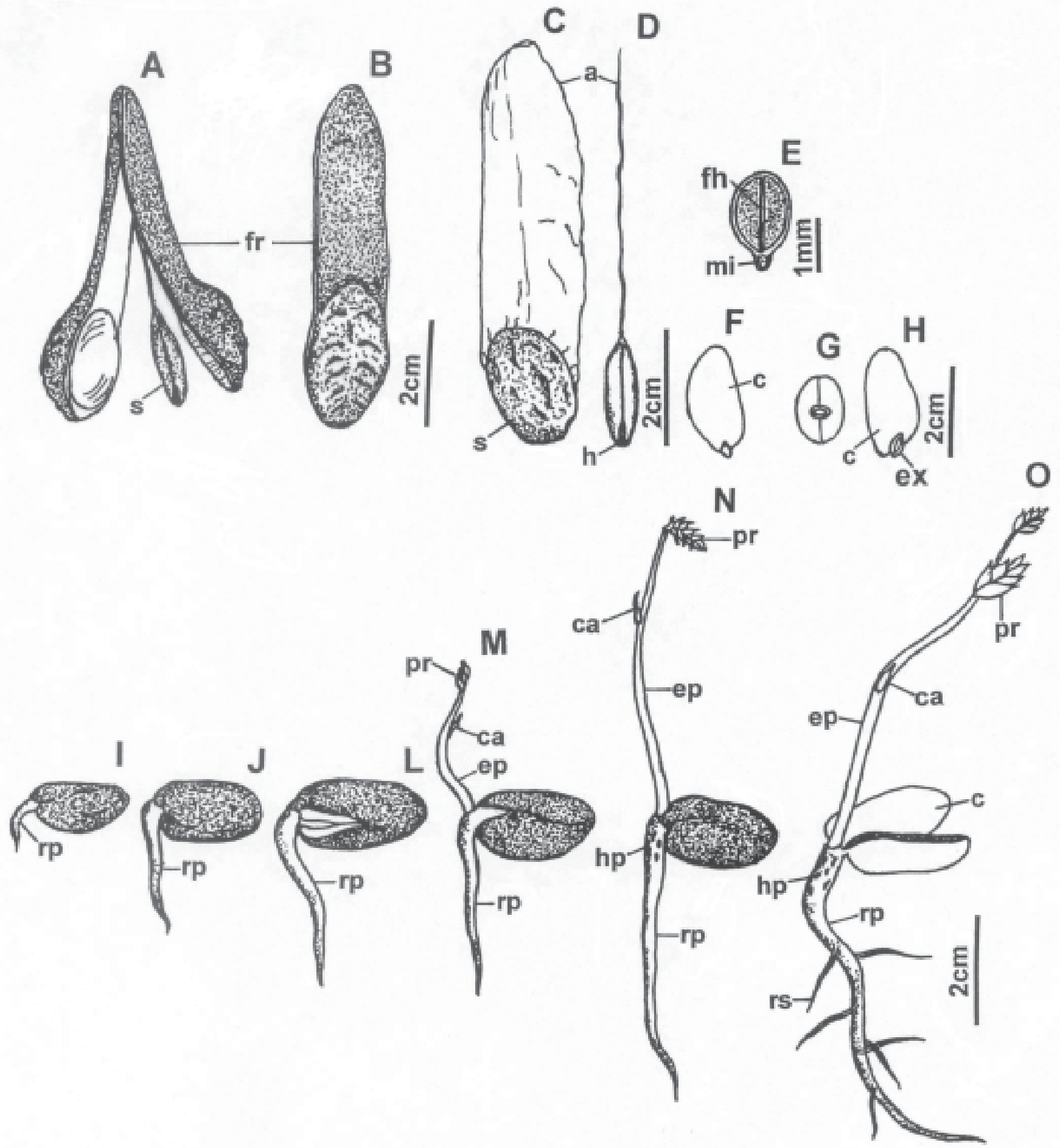

FIG. 1. Aspectos morfológicos da semente e desenvolvimento da plântula de Amburana cearensis. A - fruto aberto mostrando a semente; $B$ - fruto fechado; C-D - sementes com endocarpo adnato formando a ala; $E$ - detalhe do hilo e da micrópila; F - embrião fechado como pólo radicular visível; G - corte transversal do eixo-embrionário; H - corte longitudinal do eixo-embrionário; I-O - aspectos do desenvolvimento da plântula; a - ala; c - cotilédone; ca - catáfilo; co - coleto; em - embrião; ep - epicótilo; ex - eixo-embrionário; fh - fenda hilar; fo - folíolo; fr - fruto; h - hilo; mi - micrópila; pr protófilo; rp - raiz primária; rs - raiz secundária; s - semente. 
compostos pinados, imparipenados, curto peciolados com 3 a 5 folíolos. Os folíolos são discolores, curto peciolados, elípticos, margem inteira, ápice agudo e base obtusa, pilosos na face abaxial, nervação peninérvea, com nervuras secundárias e terciárias pouco evidentes. A gema apical apresenta-se bem desenvolvida desde o início da germinação e pode ser vista quando se promove a abertura dos cotilédones.
De acordo com a classificação de Miquel (1987), a espécie apresenta germinação do tipo semi-hipógea fanerocotiledonar.

Aspectos morfológicos da planta jovem (Figuras 2 e 3) - A raiz primária apresenta coloração amarelo pardo e, nesta fase, aumenta a intensidade de raízes secundárias e terciárias. Após 116 dias em viveiro foi observado que a raiz principal

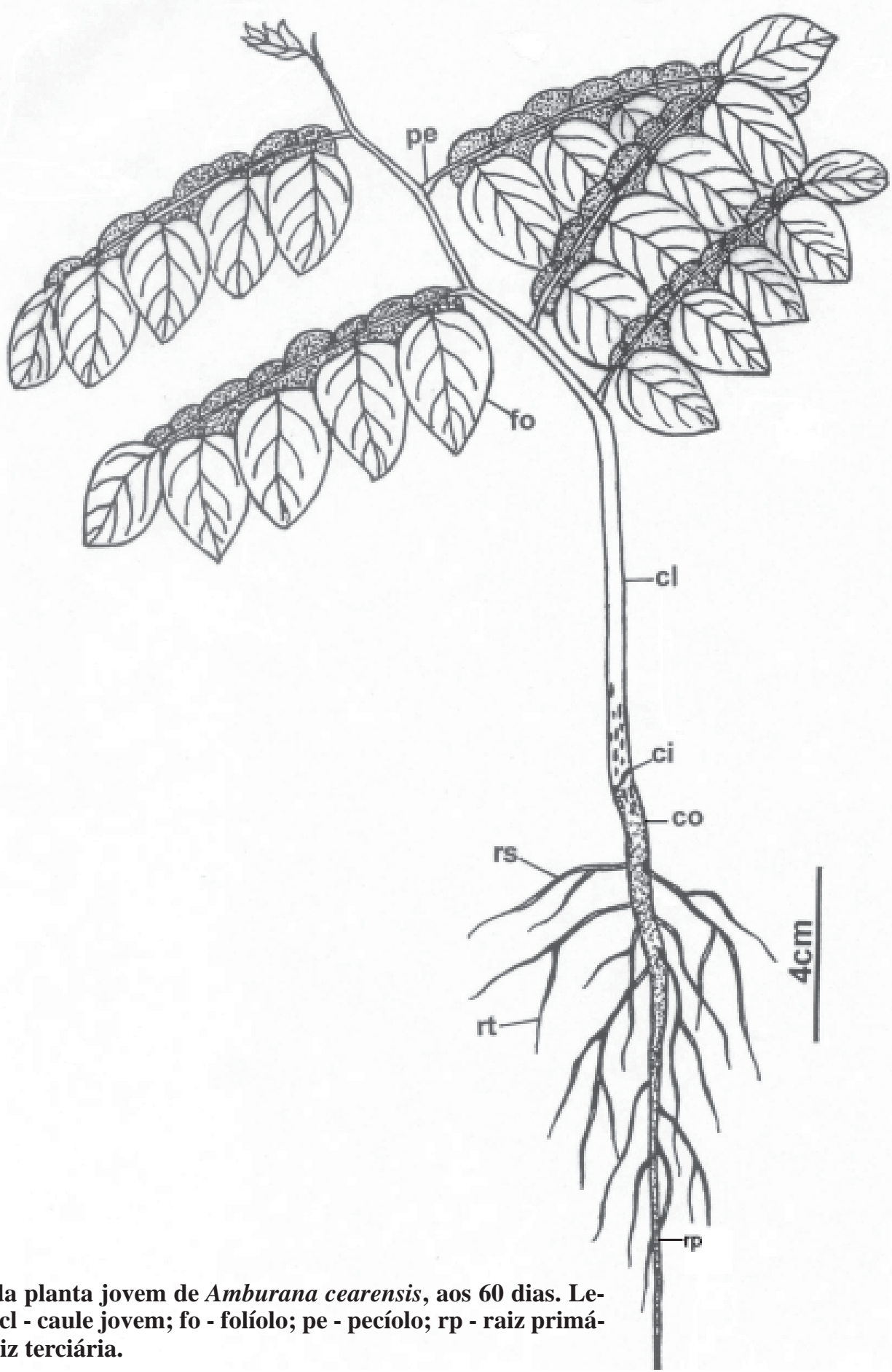

FIG. 2. Aspectos do desenvolvimento da planta jovem de Amburana cearensis, aos 60 dias. Legenda: ci - cicatriz; co - coleto; cl - caule jovem; fo - folíolo; pe - pecíolo; rp - raiz primária; rs - raiz secundária; rt - raiz terciária. 

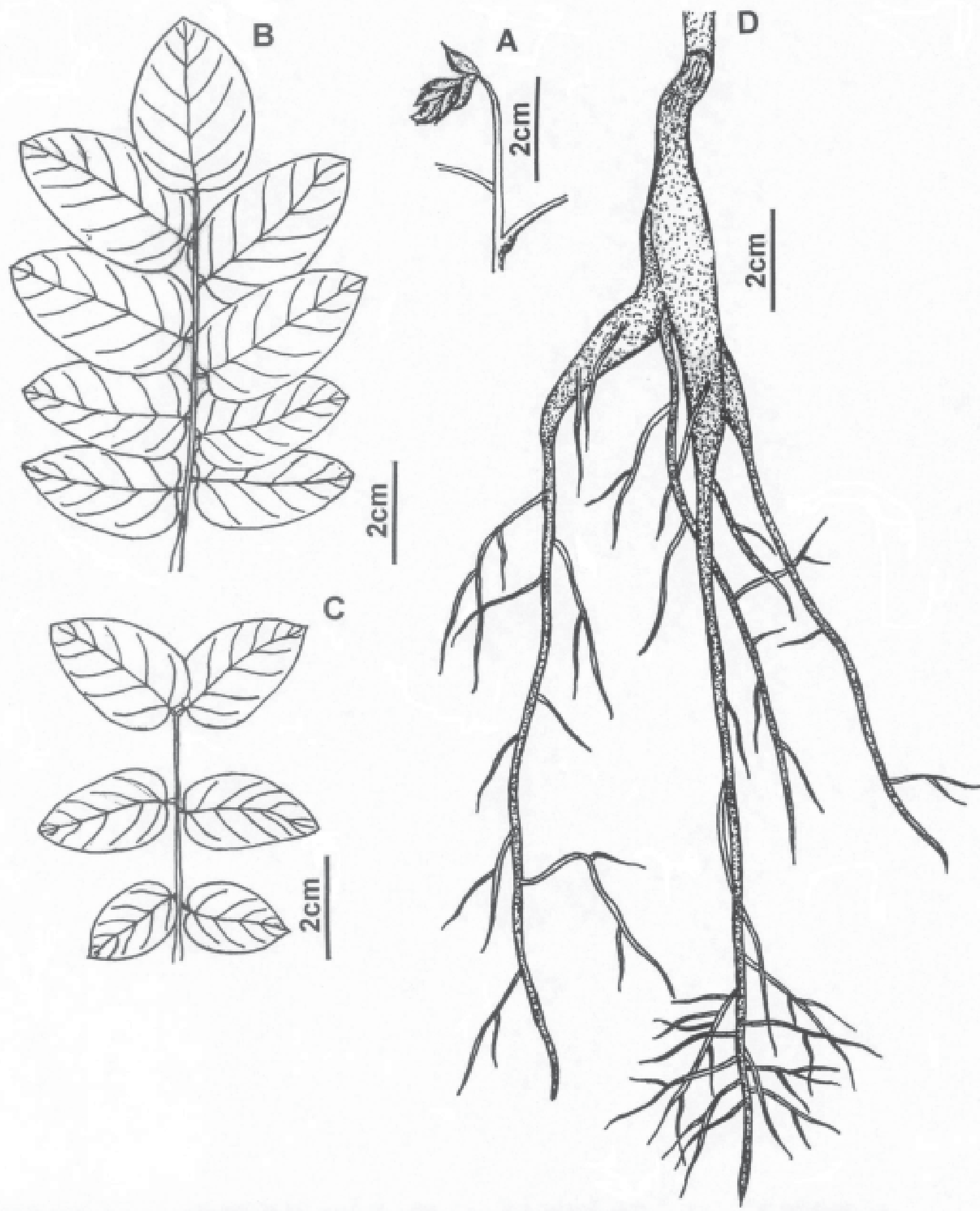

FIG. 3. Aspectos do desenvolvimento da planta jovem de Amburana cearensis, aos 116 dias de idade. A - folha em desenvolvimento B-C - aspectos da folha madura imparipenada e paripenada, respectivamente; D - raiz tuberosa. 
sofreu um espessamento, formando uma tuberosidade. O caule jovem apresenta coloração verde escuro, cilíndrico, com densa pilosidade esbranquiçada e, com catáfilo presente que deixa cicatriz após a sua queda. As folhas são compostas pinadas, com 5 a 9 pinas, alternas, longo pecioladas, imparipenadas e raras vezes paripenadas na mesma muda. O pecíolo é de coloração verde, piloso, com pulvino. Os folíolos são curtopeciolados, elípticos, com base obtusa e ápice agudo, margem inteira, nervação peninérvea evidente na face abaxial, ao contrário da adaxial e apresentam pêlos simples. Os cotilédones, quando caem, deixam cicatriz no caule. Numa das matrizes constatou-se heterofilia.

A presença de raiz tuberosa em $A$. cearensis também foi observada por Feliciano (1989). De acordo Labouriau (1964), a presença de raiz tuberosa torna a espécie capaz de resistir às condições adversas do meio e, segundo Rizzini (1965), tal estrutura constitui-se uma estratégia adaptativa que tem alto poder de rebrotamento, quando ocorre algum dano à parte aérea.

\section{CONCLUSÕES}

As sementes, plântulas e plantas jovens de Amburana cearensis apresentaram os caracteres morfológicos bastante homogêneos entre as cinco matrizes coletadas, com exceção de uma das matrizes que apresentou folhas heterófilas na fase de planta jovem. Deste modo, são bastante confiáveis para identificação, podendo ser empregados em estudos com diversas finalidades, tais como identificação de lotes de sementes e testes de germinação em laboratório, produção e identificação de mudas em viveiro e, em estudos de regeneração natural, facilitando a identificação no campo.

\section{REFERÊNCIAS}

ARAÚJO, S.S.; MATOS, V.P. Morfologia da semente e de plântula de Cassia fistula L. Revista Árvore, Viçosa, v.15, n.3, p.217-223, 1991.

BARROSO, G.M. Sistemática de Angiospermas do Brasil. Viçosa: UFV, 1984. v.3, 326p.

BARROSO, G.M.; MORIM, M.P.; PEIXOTO, A.L.; ICHASO, C.L.F. Frutos e sementes: morfologia aplicada à sistemática de dicotiledôneas. Viçosa: UFV, 1999. 443p.

BELTRATI, C.M. Morfologia e anatomia de sementes. Rio Claro: UNESP, Dep. de Botânica/ Instituto de Biociências, 1992. 108p. (Apostila do Curso de Pós-Graduação).

BRAGA, R. Plantas do Nordeste, especialmente do Ceará. 3 ed. Fortaleza: ESAM, 1976. 510p.
CORREA. M.P. Dicionário das plantas úteis do Brasil. Rio de Janeiro: IBDF, 1978. v.5, 687p.

FELICIANO, A.L.P. Estudo da geminação de sementes e desenvolvimento da muda, acompanhado de descrições morfológicas de dez espécies arbóreas ocorrentes no semi-árido nordestino. Viçosa: UFV, 1989. 114p. (Dissertação Mestrado).

FERREIRA, R.A.; CUNHA, M.C.L. Aspectos morfológicos de sementes, plântulas e desenvolvimento da muda de craibeira (Tabebuia caraiba (Mart.) Bur.) - Bignoniaceae e pereiro (Aspidosperma pyrifolium Mart.) - Apocinaceae. Revista Brasileira de Sementes, Brasília, v.22, n.1, p.134-143, 2000.

GUNN, C.R. Seed collecting and identification. In: KOZLOWSKI, T.T. Seed biology. New York: Academic Press, 1972. v.1, p.1-20.

GUNN, C.R. Seed topography in the Fabaceae. Seed Science \& Tecnology. Beltsville: Maryland, v.9, n.3, p.737-757, 1981.

KUNIYOSHI, Y.S. Morfologia da semente e da germinação de 25 espécies arbóreas de uma floresta com araucária. Curitiba: UFPR, 1983. 233p. (Dissertação Mestrado).

LABORIAU, L.G.; VÁLIO, I.F.M.; HERINGER, E.P. Sobre o sistema reprodutivo de plantas dos cerrados. Anais da Academia Brasileira de Ciências, Rio de Janeiro, v.36, n.4, p.449-464, 1964.

LAWRENCE, G.H.M. Taxonomia das plantas vasculares. Lisboa: Fundação Caluste Gulbekian, 1973. v.1, 296p.

LORENZI, H. Árvores brasileiras: manual de identificação e cultivo de plantas arbóreas nativas do Brasil. Nova Odessa: Ed. Plantarium, 1992. 352p.

MIQUEL, L. Morfologie fonctionele de plantules d'espécies forestiers du Gabon. Bull. Mus. Natn. Nat. Paris, n.1, p.101-121, 1987.

OLIVEIRA, E.C. Morfologia de plântulas florestais. In: AGUIAR, I.B.; PIÑA-RODRIGUES, F.C.M. \& FIGLIOLA, M.B. Sementes florestais tropicais. Brasília: ABRATES, 1993. p.175-214.

PINHEIRO, A.L. Estudos de características dendrológicas, anatômicas e taxonômicas de Meliaceae na microrregião de Viçosa. Viçosa: UFV, 1986. 192 p. (Dissertação Mestrado).

PINHEIRO, A.L.; RAMALHO, R.S.; VIDAL, W.N.; VIDAL, M.R.R. Estudos dendrológicos com vistas à regeneração natural de Meliaceae na microrregião de Viçosa. I. Identificação e descrição de dez espécies. Revista Árvore, Viçosa, v.13, n.1, p.1-66, 1989.

RIZZINI, C.T. Estudos preliminares sobre o xilopódio e outros órgãos tuberosos de plantas do cerrado. Anais da Academia Brasileira de Ciências, Rio de Janeiro, v.37, n.1, p.87-113, mar. 1965.

RIZZINI, C.T. Tratado de fitogeografia do Brasil. São Paulo: USP, v.2, 1979. 374p.

RODERJAN, C.V. Morfologia do estádio juvenil de 24 espécies arbóreas de uma floresta com araucária. Curitiba: UFPR, 1983. 148p. (Dissertação Mestrado).

SALLES, H.G. Expressão morfológica de sementes e plântulas I. Cephalocereus fluminensis (Miq.) Britton e Rose (Cactaceae). Revista Brasileira de Sementes. Brasília, v.9, n.1, p.73-81, 1987. 
SILVA, L.M.M.; MATOS, V.P. Morfologia da semente e da germinação de Erythrina velutina Willd. Revista Árvore, Viçosa, v.15, n.2, p.137-143, 1991.

SILVA, L.M.M.; MATOS, V.P. Morfologia de frutos, sementes e plântulas de catingueira (Caesalpinia pyramidalis Tul. Caesalpinaceae) e de juazeiro (Zizyphus joazeiro Mart. Rhamnaceae). Revista Brasileira de Sementes, Brasília, v.20, n.2, p.263-269, 1998.
TOLEDO, F.F.; MARCOS-FILHO, J. Manual de sementes: tecnologia da produção. São Paulo: Ed. Agronômica Ceres, 1977. 224p.

TIGRE, C.B. Silvicultura para as matas xerófilas. Fortaleza: DNOCS, 1968. 175p.

VIDAL, V.N. Considerações sobre as sâmaras que têm ala paranuclear. Rodriguesia, Rio de Janeiro, v.30, n.47, p.109-168, 1978.

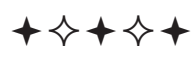

